\title{
Nivolumab Induced Seronegative Arthritis in a Patient With Refractory Hodgkin's Lymphoma
}

\author{
Seda ÇOLAK@, Ahmet OMMA® \\ Department of Rheumatology, Ankara Numune Training and Research Hospital, Ankara, Turkey
}

\begin{abstract}
Nivolumab is a monoclonal antibody against programmed cell death protein-1 which is assessed in the group of immune checkpoint inhibitors. It may lead to immune-related adverse events. In this article, we report a 38-year-old male patient diagnosed with seronegative arthritis after nivolumab therapy. This case supports that clinicians should be attentive for immune-related adverse events after use of immune checkpoint inhibitors.

Keywords: Immune-related adverse events; nivolumab; seronegative arthritis.
\end{abstract}

Nivolumab is known to be a type of immune checkpoint inhibitors (ICIs) that targets programmed cell death protein-1 (PD-1). It is commonly used in the treatment protocols of malignant melanoma, Hodgkin's lymphoma, renal cell, squamous and nonsquamous lung cancers. ${ }^{1,2}$ ICIs may cause immune-related adverse events (IRAEs). In this article, we report a case diagnosed with seronegative arthritis after nivolumab therapy.

\section{CASE REPORT}

A 38-year-old male patient was admitted to our rheumatology outpatient clinic due to pain and swelling in his hands lasting for two days. He was diagnosed as Hodgkin's lymphoma in 2007 and had been treated with nivolumab. Before the $10^{\text {th }}$ infusion, the symptoms occurred. He had no medical history except for Hodgkin's lymphoma and no similar disease in his family history. In physical examination, he had swollen metacarpophalangeal joints and edema in both hands (Figure 1). According to laboratory tests, renal and liver functions were within normal range: white blood cells: $3,200 / \mu \mathrm{L}(4,400-11,000)$, neutrophils: $1,400 / \mu \mathrm{L}(1,800-7,800)$, hemoglobin: $12.3 \mathrm{~g} / \mathrm{dL}$ (13.5-17.5), platelets: 239,000/ $\mathrm{LL}$ (150,000-450,000), C-reactive protein: $30 \mathrm{mg} / \mathrm{L}$ (0-5), and erythrocyte sedimentation rate: $36 \mathrm{~mm} /$ hour (0-20). Antinuclear antibody, anticyclic citrullinated peptide antibody, rheumatoid factor, bacteriological and viral tests were negative. Urine analysis was normal. There were soft tissue swelling and metal artifacts due to previous trauma in hand radiographs (Figure 2). Treatment with prednisolone $10 \mathrm{mg} /$ day was started due to the diagnosis of seronegative arthritis. After rheumatologic symptoms recovered, steroid therapy was tapered promptly. Nivolumab therapy was pursued during the rheumatologic involvement. A written informed consent was obtained from the patient.

Received: May 29, 2018 Accepted: July 30, 2018 Published online: September 05, 2018

Correspondence: Seda Çolak, MD. Ankara Numune Eğitim ve Araştırma Hastanesi Romatoloji Kliniği, 06230 Altındağ, Ankara, Turkey. Tel: +90 312 - 5084365 e-mail: sedayurumez@hotmail.com 

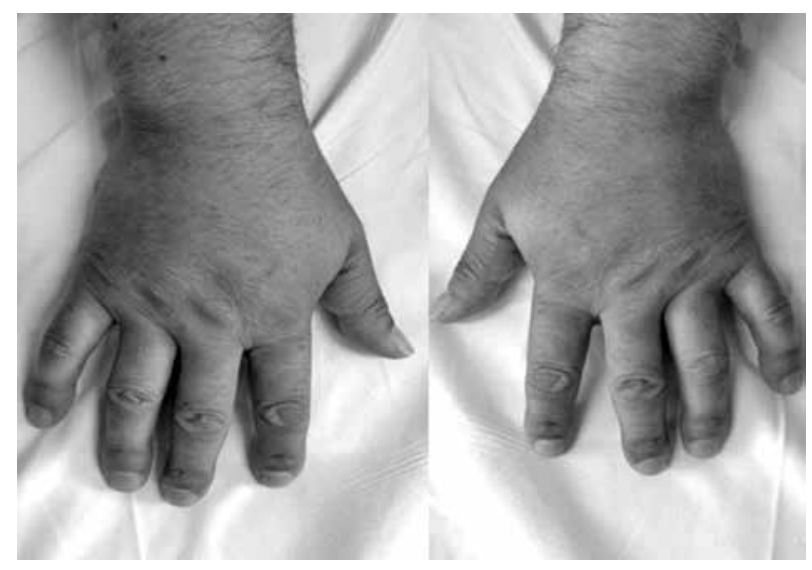

Figure 1. Photos of both hands: Swollen metacarpophalangeal joints and edema in both hands.

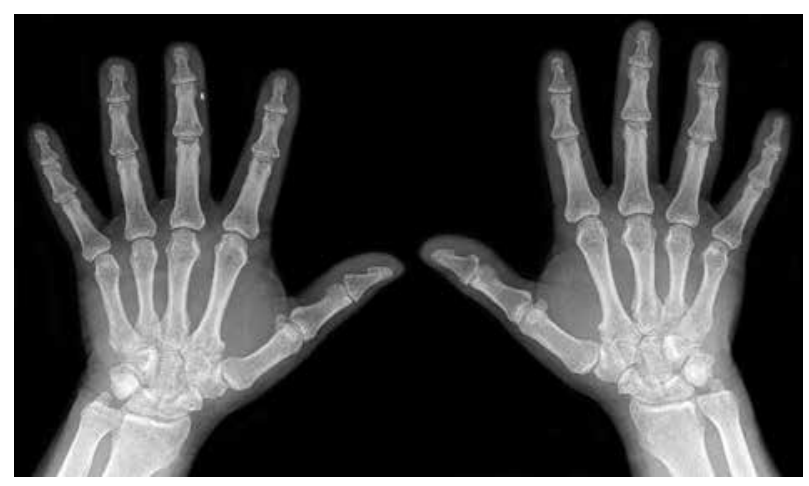

Figure 2. Anteroposterior radiographs of both hands: Soft tissue swelling and metal artifacts due to previous trauma.

\section{DISCUSSION}

Nivolumab is a monoclonal antibody that inhibits programmed death-ligand 1 binding with PD-1 and restricts T-cell inactivation against cancer cells. Consequently, both inhibition of autoimmunity regulation and unrestrained T-cells provoke IRAEs. The frequency of IRAEs depends on the drug used and type of the cancer., The percentage of IRAEs with nivolumab was reported to be $10-15 \% .{ }^{5}$ Skin manifestations and elevated transaminases can be seen at an approximate rate of $30 \%$. Severe IRAEs like colitis, pneumonitis or hepatitis are rare but they can be life-threatening. ${ }^{5,6}$ The incidence of musculoskeletal IRAEs has not been clarified yet and may be higher than shown in the literature. Different cases diagnosed with arthralgia, polymyalgia rheumatica, psoriatic arthritis, rheumatoid arthritis, myositis, myopathy, sarcoidosis, sicca syndrome, and systemic lupus erythematosus following nivolumab therapy were reported in the literature. .-9 $^{-9}$ Arthralgia may be seen more frequently. ${ }^{10}$ Capelli et al. ${ }^{6}$ reported that inflammatory arthritis occurred among 9 of 13 patients who received ICIs therapy in the form of only nivolumab or in combination with other ICIs. Similarly, Belkhir et al. $^{8}$ reported that following ICIs therapy of 10 patients without pre-existing rheumatologic disease, rheumatoid arthritis developed in six patients while polymyalgia rheumatica occurred in the rest.

Nivulomab therapy was continued in our patient in accordance with recommendations. ${ }^{11}$ and combined with low dose glucocorticoid. Glucocorticoid was tapered promptly in order to inhibit possible negative effects on cancer treatment. Clinical symptoms improved dramatically by the treatment.

Rheumatologists should be aware of the rheumatologic manifestations that can be seen in malignancies, as a paraneoplastic syndrome or an adverse effect of drugs. Currently, ICIs are promising and being used among oncology patients in a widespread manner. Thus, awareness of clinicians about IRAEs is becoming more important in the treatment process.

\section{Declaration of conflicting interests}

The authors declared no conflicts of interest with respect to the authorship and/or publication of this article.

\section{Funding}

The authors received no financial support for the research and/or authorship of this article.

\section{REFERENCES}

1. Brahmer JR, Tykodi SS, Chow LQ, Hwu WJ, Topalian SL, Hwu P, et al. Safety and activity of anti-PD-L1 antibody in patients with advanced cancer. N Engl J Med 2012;366:2455-65.

2. Beköz H, Karadurmus N, Paydas S, Türker A, Toptas T, Firatli Tuglular T, et al. Nivolumab for relapsed or refractory Hodgkin lymphoma: real-life experience. Ann Oncol 2017;28:2496-2502. 
3. Wang PF, Chen Y, Song SY, Wang TJ, Ji WJ, Li SW, et al. Immune-Related Adverse Events Associated with Anti-PD-1/PD-L1 Treatment for Malignancies: A Meta-Analysis. Front Pharmacol 2017;8:730.

4. Villadolid J, Amin A. Immune checkpoint inhibitors in clinical practice: update on management of immunerelated toxicities. Transl Lung Cancer Res 2015;4:560-75.

5. Widmann G, Nguyen VA, Plaickner J, Jaschke W. Imaging Features of Toxicities by Immune Checkpoint Inhibitors in Cancer Therapy. Curr Radiol Rep 2016;5:59.

6. Cappelli LC, Gutierrez AK, Baer AN, Albayda J, Manno RL, Haque U, et al. Inflammatory arthritis and sicca syndrome induced by nivolumab and ipilimumab. Ann Rheum Dis 2017;76:43-50.

7. Abdel-Rahman O, Eltobgy M, Oweira H, Giryes A, Tekbas A, Decker M. Immune-related musculoskeletal toxicities among cancer patients treated with immune checkpoint inhibitors: a systematic review. Immunotherapy 2017;9:1175-83.

8. Belkhir R, Burel SL, Dunogeant L, Marabelle A, Hollebecque A, Besse B, et al. Rheumatoid arthritis and polymyalgia rheumatica occurring after immune checkpoint inhibitor treatment. Ann Rheum Dis 2017;76:1747-50.

9. Ruiz-Bañobre J, Pérez-Pampín E, García-González J, Gómez-Caamaño A, Barón-Duarte FJ, López-López $\mathrm{R}$, et al. Development of psoriatic arthritis during nivolumab therapy for metastatic non-small cell lung cancer, clinical outcome analysis and review of the literature. Lung Cancer 2017;108:217-21.

10. Buder-Bakhaya K, Benesova K, Schulz C, Anwar $\mathrm{H}$, Dimitrakopoulou-Strauss A, Weber TF, et al. Characterization of arthralgia induced by PD-1 antibody treatment in patients with metastasized cutaneous malignancies. Cancer Immunol Immunother 2018;67:175-182.

11. Puzanov I, Diab A, Abdallah K, Bingham CO 3rd, Brogdon C, Dadu R, et al. Managing toxicities associated with immune checkpoint inhibitors: consensus recommendations from the Society for Immunotherapy of Cancer (SITC) Toxicity Management Working Group. J Immunother Cancer 2017;5:95. 